\title{
Theoretical Frontiers in Representative Bureaucracy: New Directions for Research
}

\author{
Kenneth J. Meier*,+ \\ ${ }^{*}$ American University; ${ }^{\dagger}$ Cardiff University \\ Address correspondence to the author at kmeier@american.edu.
}

\begin{abstract}
The notion of a representative bureaucracy has generated a great deal of research although many issues are yet to be resolved and some have not been addressed. This theoretical essay uses a contingency theory approach to address a set of key questions relevant to representative bureaucracy. It discusses who is represented and what values get represented at the aggregate level, why bureaucrats represent, who they represent, and which bureaucrats represent at the individual level, and the empirical issues of critical mass, intersectionality, and how representation might change as a minority becomes a majority. The essay proposes 15 testable hypotheses and four modeling recommendations for empirical analysis.
\end{abstract}

The literature on representative bureaucracy has seen a recent outpouring of empirical research (see Andrews and Miller 2013; Atkins and Wilkins 2013; Gade and Wilkins 2013; Hong 2016, 2017; Riccucci, Van Ryzin, and Lavena 2015; Riccucci, Van Ryzin, and Li 2016 among others) as well as essays on the state of the field (Kennedy 2014; Riccucci and Van Ryzin 2017) and some attempts to link to other concepts (Ashikali and Groeneveld 2015) or generate new theoretical insights (Groeneveld et al. 2015; Groeneveld and Van de Walle 2010; Meier and Morton 2015). These studies reflect the general belief that bureaucracy in the aggregate should look like those it serves because this is one way to ensure that diverse interests are considered in the decisions made by government organizations (see Riccucci and Van Ryzin 2017 among others). After decades of research, however, the evidence is mixed in terms of the translation of demographic representation into public policy outputs and outcomes. Although the

I would like to thank Seung-ho An, Rhys Andrews, M. Apolonia Calderon, Sandra Groeneveld, Lael Keiser, Brandy Kennedy, Norma Riccucci, Amanda Rutherford, Miyeon Song, Vicky Wilkins, and Kenicia Wright for offering helpful comments on earlier drafts. Miyeon Song provided the graphics. body of work has advanced representative bureaucracy incrementally, we need to take a holistic approach to identifying an empirical model that would consider the various factors that have emerged in the literature in the recent years. The essay will reexamine some essential concepts, parse the meaning of theoretical arguments in the current literature, model some basics in the theory, and illustrate some new approaches. It does so by linking representative bureaucracy with other theories of bureaucratic behavior and organizational context. The overall objective is to present some new and interesting topics for discussion and hypotheses for testing.

This theoretical essay unfolds in four parts. First, the theory of representative bureaucracy specifies several conditions that affect that translation of passive representation (PR) into active representation (AR). A useful way to view these conditions is as a form of contingency theory that can be modeled as a series of interactive relationships. Second, two issues of representation at the aggregate (i.e., organizational) level will be addressed-who is represented and what values are being represented? This section criticizes the argument that representative bureaucracy somehow biases 
existing neutral bureaucracies (see Lim 2006; Peters, Schröter, von Maravic 2015, 13). Third, moving from the aggregate level to the individual level, three questions in the microtheory of representative bureaucracy will be discussed-why do bureaucrats represent, who do bureaucrats represent, and which bureaucrats decide to represent? Fourth, a set of current issues in representative bureaucracy are examined-considering whether and when a critical mass is needed, examining the inherent intersectionality of bureaucrats, and discussing the case where a minority group becomes a majority group. The essay will propose four modeling recommendations (table 1) and 15 hypotheses (table 2).

\section{An Interactive Framework}

The theory of representative bureaucracy distinguishes between PR and AR. PR concerns whether bureaucrats mirror the demographic origins of the population in terms of race, gender, social class or other characteristics (Mosher 1968). AR is defined as the case when bureaucrats "act for" the publics that look like them and in the process seek to change bureaucratic outputs (Selden 1997). This essay will use the term "AR" to mean cases where the bureaucracy produces benefits for the clients that are passively represented. This is a simplification that is common in the literature (see Meier 1993; Selden 1997 among others). Representation is the process of acting for or acting in the interests of another. A bureaucrat represents an individual if the bureaucrat acts to make the client better off. Because representation is a process, it can fail. In such circumstances, there can be AR, but there will be no correlated policy benefit. Similarly, there can be policy benefits or more favorable outcomes even if bureaucrats do not represent. Such outcomes can occur because clients change their behavior when a bureaucrat looks like them (Meier and Nicholson-Crotty 2006).

The bare bone's theory of representation holds that the translation of PR into AR is contingent on the salience of the identity in question (race, gender, age, etc.) and the discretion of the bureaucrat that is linked to that identity (Keiser et al. 2002; Kennedy 2014; Selden 1997; Sowa and Selden 2003). At the aggregate level, the theoretical relationship between PR and AR can be depicted by a simple graph (figure 1) that shows a linear relationship between a measure of PR and some outcome that might benefit the individuals who are passively represented or mathematically as ${ }^{1}$ :

$$
\mathrm{AR}=\beta_{1} \mathrm{PR}+\varepsilon
$$

In situations where AR does not occur, the slope of this line goes to zero; and there is no relationship between
PR and the AR outcome. All other things being equal, as the salience of the identity and the level of discretion available increase, the slope of this line should increase. If the bureaucrat's discretion is not linked to the identity in question, bureaucratic representation cannot occur. If the salience of the identity is low (e.g., social class in the United States), the motivation for bureaucratic representation will approach zero. These basic principles can be generalized to contextual theories of representative bureaucracy (Groeneveld et al. 2015; Meier and Morton 2015) where some contextual variable $(\mathrm{C})$ is posited to interact with PR to affect the level of AR (Modeling Recommendation M1, see table 1):

$$
\mathrm{AR}=\beta_{1} \mathrm{PR}+\beta_{2} \mathrm{C}+\beta_{3} \mathrm{C} * \mathrm{PR}+\varepsilon
$$

where C might be a measure of discretion (see Andrews, Ashworth and Meier 2014; Meier and Bohte 2003; Sowa and Selden 2003), the salience of an identity (Meier, Pennington, and Eller 2005), the concentration of political power (Groeneveld et al. 2015), organizational stratification (Keiser et al. 2002), the gendered nature of the policy area (Smith and Monaghan 2013, 52-3), or any other variable that might affect the translation of PR into AR. This interactive relationship contends that the slope of the passive to active regression line (and thus the actual level of representation) is affected by the context of the bureaucratic action. ${ }^{2}$

If, as existing theory maintains (Atkins and Wilkins 2013; Meier and Morton 2015), both a salient identity and discretion in regard to decisions that link to that identity are necessary conditions for AR, then this contextual factor needs to include both variables. At a more general level, however, one could still contend that if one holds the salience of an identity constant, an increase in policy-relevant discretion should be associated with an increase in AR. Similarly, holding the level of discretion constant, an increase in the

1 The definition of bureaucratic representation is at the individual level; in many cases arguments are also presented at the aggregate or organizational level. It is also clear that clients prefer bureaucrats who look like them and, therefore, might perceive more favorable treatment from representative bureaucrats than actually exists (Gade and Wilkins 2013; Riccucci, Van Ryzin, and Lavena 2015; Theobald and Haider-Markel 2009; Thielemann and Stewart 1996). The essay will not discuss the literature on PR; a brief but comprehensive overview of that literature can be found in Riccucci and Van Ryzin (2017).

2 Groeneveld et al. (2015) distinguish between external and internal context as it affects representative bureaucracy. Internal context might include such things as organizational culture, the professional makeup of the organization, or how close supervision patterns are. External context would include a variety of political factors such as government structures, number of veto points, political ideology, or population heterogeneity. 
Table 1. Modeling Recommendations

M1: Contextual hypotheses about the impact of passive representation can be modeled as statistical interactions. Equation (2)

M2: The tradeoff between representation and equity can be modeled as diminishing returns as performance approaches equity. Equations (3 and 4)

M3: Critical mass hypotheses concerning representation need to be tested with both a critical mass interaction and the simpler representative bureaucracy relationship. Equation (6)

M4: Intersectionality is appropriately modeled via interaction terms that combine the various identities. Equation (7)

Table 2. Hypotheses for Representative Bureaucracy

H1: No bureaucracies are neutral.

$\mathrm{H} 2$ : If representative bureaucracies pursue equity rather than representation, the relationship between passive representation and active representation (AR) will be nonlinear (diminishing returns).

H3: The Generic Extrinsic Motivation Hypotheses. If a representative bureaucracy leads to increased organizational performance, bureaucrats will be more willing to adopt the role of representation.

Specific Extrinsic Hypotheses:

H3a: If performance appraisal systems emphasize assisting disadvantaged populations, representative bureaucracy will increase organizational performance.

$\mathrm{H} 3 \mathrm{~b}$ : If representative brings skills to the organization that relate to performance, representative bureaucracy will increase organizational performance.

$\mathrm{H} 3 \mathrm{c}$ : If organizational performance is affected by coproduction and clientele are diverse, representative bureaucracy will increase organizational performance.

H4: An increase in public service motivation will be associated with an increase in AR.

Individual Behavior Hypotheses

H5: Bureaucrats are more likely to act for clients who engage in coproduction.

H6: Bureaucrats are more likely to act for clients if the goals of the client match those of the bureaucrat.

H7: Bureaucrats are more likely to act for clients if the clients multiple identities closely match those of the bureaucrat.

H8: Bureaucrats are more likely to act for clients if the risk to the bureaucrat is low.

H9: Bureaucrats are more likely to act for clients who are in the greatest need.

H10: Bureaucrats are more likely to act for clients when they possess slack resources

H11: More productive bureaucrats are more likely to act for clients.

H12: Bureaucrats are more likely to act for clients when the bureaucrats have job security.

H13: Organizations characterized by racial or gender segregation by hierarchy are more likely to increase bureaucratic representation at the street level.

H14: The impact of intersectionality on representative bureaucracy is a function of the multiple identities of both the bureaucrat and the client.

H15: Minority-majority institutions (those that change such that numerical minorities in the population become a numerical majority in the organization) will have diminishing marginal returns to bureaucratic representation.

salience of an identity should correspond to an increase in AR.

\section{Issues of Aggregate Representation}

Much of the research in representative bureaucracy is examined at the aggregate level, that is, does how representative an organization is affect the total benefits provided to the represented community? This focus is theoretically justified by micro theories of representation that do not require an individual client come into contact with a specific individual bureaucrat (Meier and Morton 2015). Empirical studies of bureaucratic representation have faced normative criticisms (Bearfield 2009; Lim 2006; Peters, Schröter, and von Maravic 2015) that require further theoretical clarification and empirical investigation. The key issues can be summarized by asking who is being represented and what value is being pursued?

\section{Who Gets Represented?}

The representative bureaucracy literature focuses on the representation of the disadvantaged even though the process of representation per se does not deal with disadvantages (see Keiser's 2010 distinction between the normative and empirical theories of representation). In many ways, all bureaucracies represent. They might represent the wishes of the legislature as expressed in agency missions (Rourke 1984), the goals of powerful interests (Dal Bó 2006), or even the concept of the state as in France (Meier and Hawes 2009). In the United States, no historical study of the administrative state would challenge the contention that the Department of Agriculture was created to represent the interests of agriculture or that the Department of Commerce was intended to represent the interests of business (Mosher 1968; Rourke 1984). After all, politics is about power (the authoritative allocation of 


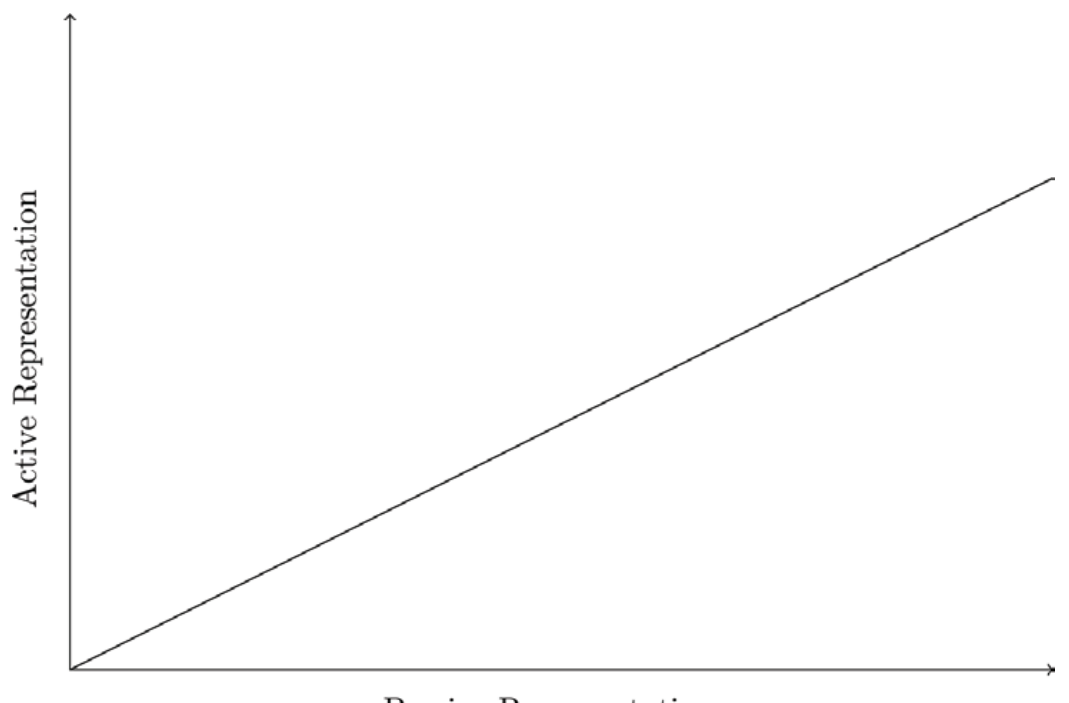

Passive Representation

Figure 1. The Hypothetical Relationship Between Passive and Active Representation.

values [Easton 1965]), and it should be no surprise that programs and organizational structures are established to benefit those with the power to control the political process. From a theoretical perspective, the representation of the advantaged is not very interesting simply because that is what many bureaucracies are designed to do. ${ }^{3}$ Far more interesting is when a bureaucrat deviates from this principle and represents the disadvantaged, those without access to powerful political allies.

Recognizing that a bureaucrat who decides to represent the disadvantaged is taking a risk is important. Bureaucracies seek bureaucrats who will further the organization's mission, and bureaucracies engage in extensive socialization of the bureaucrats to the organization and its mission (Oberfield 2014; Romzek and Hendricks 1982). If representation is not part of that mission, the bureaucracy might punish or not provide rewards to bureaucrats who tradeoff mission objectives for representation. This level of risk also makes representation of the disadvantaged an interesting area of study because at one level the bureaucrat's behavior deviates from the rational path of being an organizational member (see the section on representation at the individual level).

\section{What Value is Being Represented?}

One normative criticism in the literature on representative bureaucracy is that the process introduces favoritism (perhaps unconsciously see Akram 2018) into a bureaucratic process that the critics contend

3 I agree with the institutional work of Knight (1992) that all institutions contain biases, that there are multiple ways to solve collective action or other problems and that the choice of the institutional arrangement is strategic. is designed to be neutral (Bearfield 2009; Lim 2006; Peters, Schröter, and von Maravic 2015). Indeed one can envision bureaucracies where ethnic or family ties determine what benefits the bureaucracy will deliver to citizens, a form of patronage bureaucracy that might be common in parts of the developing world (van Gool 2008). The critics clearly have an argument that a Weberian (1946) style bureaucracy that neutrally applies rules is, in general, preferable to a corrupt bureaucracy that operates on favoritism. The fallacy in the argument, however, is that the critics are comparing a hypothetical bureaucracy (Weber's ideal-typical bureaucracy) that exists only as a theoretical ideal with a set of worst-case scenarios. The appropriate comparison is to contrast existing bureaucracies that are passively representative to those that are not (with appropriate controls for context and function).

As noted above, in the real world, all bureaucracies represent (i.e., act for someone or in accord with some principles). As Weber (1946) contended, bureaucracy is a power instrument of the first order, for the one who controls the bureaucracy. Weber's claim means that bureaucracies generally benefit the advantaged, those who can mobilize the political process to procure benefits and lock those benefits in permanently through some type of bureaucratic process. This basic principle provides the counter argument to the critics; to whit, there are no neutral bureaucracies (Hypothesis $\mathrm{H} 1$, see table 2), and the theory of representative bureaucracy only seeks to make existing bureaucracies less biased rather than more biased (see Hong 2017b for evidence of this applied to police departments in the United Kingdom). ${ }^{4}$ Extensive empirical literature verifies that advantaged individuals are more likely to benefit from bureaucratic processes in education, law 
enforcement, zoning, health care, and other services (Epp, Maynard-Moody, and Haider-Markel 2014; LaViest 2005; Lee 2002; Maantay 2001). Even in US welfare bureaucracies, the creation of rules and administrative burdens (Moynihan, Herd, and Harvey 2015) limit benefits to the relatively more advantaged (Soss 1999 ) with the more disadvantaged individuals less likely to receive services. In education, Hawes (2013) finds that representation is associated with an increase in actual interventions only when there are significant disparities between Latino and Anglo students (on this point see also Hong 2017a).

Representative bureaucracy, in this view, can be seen as an effort to lessen the inherent biases of the bureaucracy rather than infuse biases where none existed before. ${ }^{5}$ This argument raises the question as to what is the objective of the bureaucrat who adopts a representative role (Selden 1997)? The assumption has been that the goal is representation, the provision of benefits to individuals who look like the bureaucrat. Might it not be the case, however, that bureaucrats who are highly educated and likely aware of the distributional aspects of policy and bureaucracy are merely seeking to counter the existing biases of the system? Pursuing this logic, it is possible that bureaucratic representatives are seeking equity rather than representation? Although the empirical manifestations of representation versus equity are the same in most instances, there are some cases where it might be possible to distinguish between the two values.

In considering the potential tradeoff between representation and equity, a definition of equity needs to consider its various dimensions. In a classic exposition Frederickson (1990) notes that equity could be interpreted to mean equal access to opportunities (such as gifted classes, see Grissom, Rodriguez, and Kern 2017), equal outcomes (such as test scores, see Meier, Wrinkle, and Polinard 1999), or as a match between

4 An extensive literature in bureaucratic politics finds that bureaucrats possess values and seek to shape policy in accord with those values (Clinton and Lewis 2007; Downs 1967; Gailmard and Patty 2007; Hammond and Thomas 1989).

5 This argument applies only where discretion exists. When bureaucracies are established as universal systems with precise standards such as the US Social Security retirement system, then it is possible for bureaucracies to be unbiased if the rules are set up in an unbiased manner. The biases in the Social Security retirement system arose from the enabling statute that excluded groups of workers (domestics, farm workers) more likely to be African American and by a retirement formula based in part on pre-retirement earnings (Lieberman 2001). These are biases in the statute not biases in the bureaucracy. Ostensibly universal programs, however, can still be biased in the bureaucracy. The Social Security disability programs, the unemployment insurance program, and portions of the GI Bill providing benefits for veterans allowed for local implementation that resulted in discrimination based on race, discrimination that reflected the racial preferences of the politically advantaged (Katznelson 2005). need and services (as in child support see Wilkins and Keiser 2004). Equity can be interpreted in any of these meanings; what all of them imply is that there will be advocacy up to the point of equity but not beyond that point, unlike representation which should continue to apply.

If equity rather than representation is the value sought by representative bureaucrats, then how bureaucratic behavior changes as the disadvantaged group approaches relative equity (in terms of policy outcomes or access) becomes a key test case. Figure 2 presents such a hypothetical scenario. Assume a disadvantaged group that constitutes $\mathrm{X}$ percent of the agency clientele (e.g., African-American students are $20 \%$ of the school population), and this group constitutes $\mathrm{Z}$ percent of the clientele with a positive outcome (e.g., African-American students are $10 \%$ of the students in gifted classes). As long as $\mathrm{X}<\mathrm{Z}$, then a bureaucrat who pursues representation cannot be distinguished from one seeking equity. As $\mathrm{X}$ approaches and exceeds $\mathrm{Z}$, however, the two processes become distinct. A bureaucrat seeking representation (but not equity) will continue to press for more benefits for the individuals of this class; the equity-seeking bureaucrat, in contrast, will reduce efforts in this direction (perhaps to focus on other areas). The figure, thus, shows a strictly linear relationship for representation (the dashed line) but a nonlinear relationship for equity (the solid line) that asymptotically approaches the equitable ratio (Hypothesis $\mathrm{H} 2$ ). ${ }^{6}$

In terms of existing theory, this logic suggests that as a clientele group approaches equity in aggregate terms, the salience of the identity will decline and thus pressures to represent will ease. Hong's (2017) study of Welsh and English police forces, for example, shows that the impact of changes racial representation is larger in jurisdictions that previously engaged in the most inequitable policing tactics. Jurisdictions with relatively equitable treatment of minority citizens saw little additional shift in policies consistent with this hypothesis. This equity versus representation relationship can also be tested in cases where a disadvantaged group has become an advantaged group or where a generally disadvantaged group has some local advantages. As an example, women are a traditionally disadvantaged group in the United States, but over the last several decades women are both more likely to attend college and, of those attending, are more likely to graduate. This generalization holds across all racial

\footnotetext{
6 The relationship might not be as precise as this since there is always some uncertainty in making decisions. Bureaucrats might not be aware of exactly on which side of the equity standard the organization currently is on, or some outcomes such as graduation rates are dependent on decisions that were made several years earlier with some probabilistic outcome.
} 


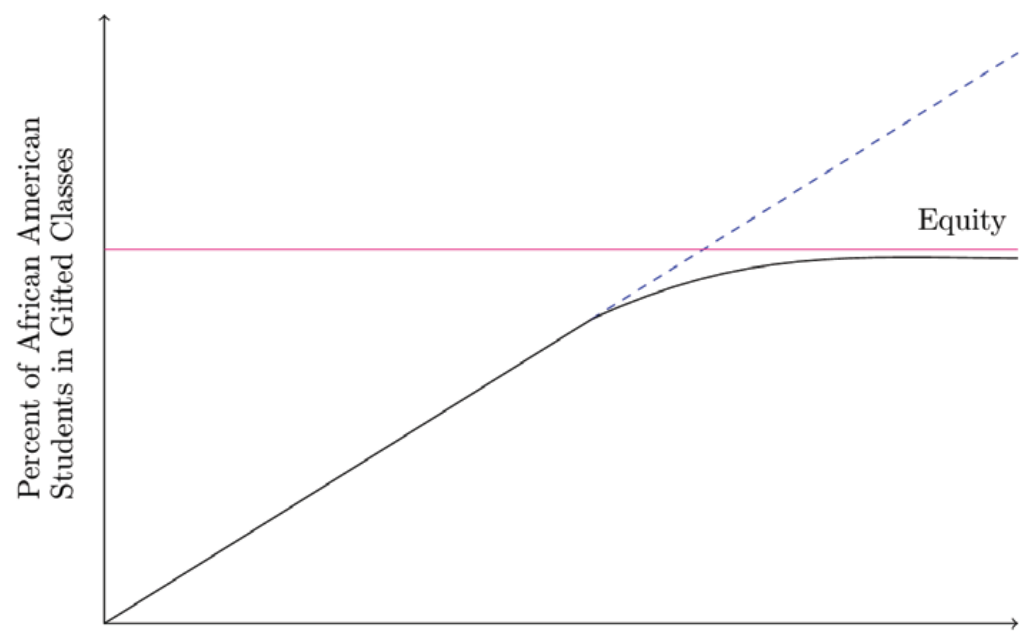

Percent of African American Students in the School

Note. Dashed line indicates focus on representation only. The curved line indicates a focus on equity rather than solely representation.

Figure 2. The Relationship between Passive and Active Representation as Outcomes Become More Equitable.

groups (Bailey and Dynarski 2011). If equity rather than representation is the goal, then gender representation which is strong in K-12 education (Keiser et al. 2002) should not be reflected in the college graduation rates for women students, particularly for white women students who have the highest graduation rates of any race-gender cohort. ${ }^{7}$

The equity versus representation tradeoff might also be examined in cases where only some organizations approach equity (as opposed to an entire class such as white women and college graduation rates). In that case one could simply add a nonlinear term to basic equation (1) by either a squared term (3) or a reciprocal (1/PR) (4):

$$
\begin{aligned}
& \mathrm{AR}=\beta_{1} \mathrm{PR}+\beta_{2} \mathrm{PR}^{2}+\varepsilon \\
& \mathrm{AR}=\beta_{1} \mathrm{PR}+\beta_{2} / \mathrm{PR}+\varepsilon
\end{aligned}
$$

7 In addition to its consistency with Hong's (2017) study of police, the equity hypothesis also explains a set of anomalies in the representative bureaucracy literature. Nicholson-Crotty, Grissom, and NicholsonCrotty (2011), for example, find the association of African-American faculty with greater assignments of African-American children to gifted classes dissipates in organizations where black students approach equity in assignments. Keiser et al.'s (2002) study of gender in education demonstrates that although female teachers benefit female students, they have no detrimental impact on male students (in fact, the impact is also positive); these findings parallel findings of Meier, Wrinkle, and Polinard (1999) on the impact of minority teachers on test scores for minority and nonminority students. Additional work shows that in nonzero sum situations, representation of one minority group frequently benefits not just the represented minority but also other minorities in the organization (Keiser and Hawes 2007; Meier et al. 2001; Rocha and Hawes 2009).
The significance of the second term in equation (4) would indicate the equity pattern in figure 2 of asymptotically approaching equity. Equation (3) would also fit this pattern within a more limited range by indicating diminishing marginal returns (Modeling Recommendation M2).

This discussion of equity versus representation has assumed that the bureaucrat views the world only in terms of the organization's operations, that is, is only interested in dealing with inequality as it originates in the actions of the organization. An alternative view is that the bureaucrat perceives that the organization needs to compensate for general inequities in society and, therefore, seeks greater than proportionality to try and counterbalance broader social inequities. If this is the case, distinguishing between equity and representation will not be possible. ${ }^{8}$

The argument presented here might be made even more provocatively to argue that the whole idea of a neutral bureaucracy is to treat individuals equitably and that representative bureaucracy is merely a correction for an existing bureaucratic pathology or a failure to consider existing societal inequities. Clearly, the objective of Weber's ideal-typical bureaucracy was to treat all individuals in the same situation equally. A neutral application of rules, however, cannot necessarily overcome existing inequalities in society based on race, ethnicity, socioeconomic status, or gender. Because the literature on representative bureaucracy has focused on inequalities based on race and gender rather than socioeconomic status or disparities in political power, it might have obscured the possible

8 I would like to thank an anonymous reviewer for this insight. 
commonalities between representation and equity in bureaucratic decisions.

\section{Representation at the Individual Level}

Aggregate forms of representation are, of course, a combination of individual bureaucratic actions including direct action by the minority bureaucrat, influencing majority bureaucrats, contributing to policy change in the organization, or other factors. This recognition means that examining the micro-theory behind individual bureaucratic actions can provide important insights for scholars.

\section{Why Do Bureaucrats Represent?}

Both theoretical literature and empirical findings indicate that PR is not always translated into AR (Keiser et al. 2002; Peters et al. 2015; Wilkins and Williams 2009). The theoretical literature discusses a wide range of barriers to representation (Groeneveld and Van de Walle 2010; Meier and Morton 2015). The primary barrier (assuming salience and discretion) is that organizations socialize their employees to the values of the organization and reinforce this socialization with various rewards (promotions, raises) and punishments (Oberfield 2014; Romzek and Hendricks 1982). Unless a bureaucracy's mission is to represent the disadvantaged (e.g., the US Equal Employment Opportunity Commission [EEOC]), bureaucratic organizations generally seek to squeeze out values arising from nonorganizational sources such as race, ethnicity, gender, etc. ${ }^{9}$ A bureaucrat aspiring to represent or as Selden (1997) states it, adopt the "role of the representative" takes some personal risks and incurs some transactions costs. A rational bureaucrat would not act as a representative unless that role somehow provided more benefits than costs (see also Carroll 2017). ${ }^{10}$

Both extrinsic and intrinsic rewards in a representation role may exist to compensate for the potential costs of representation. Extrinsic benefits occur when

9 Organizations that are designed to represent the disadvantaged are an interesting case of representative bureaucracy that has not been fully studied. In addition to the EEOC, the US Office for Civil Rights in the Department of Education, and historically the Women's Bureau in the Department of Labor are examples. At the state level, several public utility commissions have offices that are designed to represent the interests of consumers. If one considers the world of nonprofit organizations, there are many organizations which are created to represent children, poor people, the homeless, immigrants, and others who are generally disadvantaged. Many non-US examples can also be found.

10 It is usual to apply the logic of rational choice to representative bureaucracy (exceptions are Carroll 2017; Meier and Morton 2015), but such models are applied generally to why bureaucrats act as they do (Downs 1967; Gailmard and Patty 2007). Because representation involves the use of discretion, models of choice should provide some insights as to why bureaucrats represent. the organization recognizes the benefits of the representation and provides rewards for that behavior (Hypothesis H3). This occurs when representation generates a more effective or more efficient process. Setting aside the provocative claim of Meier, Wrinkle, and Polinard (1999; Meier et al. 2001) that more representative bureaucracies perform better because they do not discriminate in the labor markets, there are cases where representative bureaucracy provides net benefits to the organization that the organization should then reward.

First, if the organization operates under a performance appraisal system that requires performance across subgroups of the population, then representation focused on these subgroups may benefit the organization (Hypothesis 3a). This was the case under the US No Child Left Behind Law that required schools to meet performance standards for all subgroups of students as well as overall (Manna 2006, 2010). ${ }^{11}$ If representative bureaucracy improves the performance of minority students, then the organization as a whole benefits.

Second, if the representation role brings a skill that enhances overall performance, the organization will benefit (Hypothesis 3b). As an example, a police force that hires Latino officers will be more likely to gather crime-solving information in Latino communities, especially if the officer speaks Spanish (Calderon 2018).

Third, organizational effectiveness might be enhanced in cases where organizations rely on coproduction and the match of a client and a bureaucrat changes the dynamics of their interactions. Meier and Nicholson-Crotty (2006) demonstrate that police forces with more women are associated with a greater willingness to report sexual assaults and a higher arrest rate for such crimes (see also Hong $2017 \mathrm{~b}$ ). Both experimental and survey research indicates that clients prefer bureaucrats who look like them and view bureaucratic actions more favorably in those situations (Riccucci, Van Ryzin, and Lavena 2015; Riccucci, Van Ryzin, and Li 2016; Theobald and Haider-Markel 2009). To the extent that these variables improve the coproduction relationship (see Vinopal 2017 on parental involvement in schools), the organization benefits from a more representative bureaucracy (Hypothesis 3c). In all three cases, a rational organization would encourage bureaucrats to adopt the role of the representative and should reward such behaviors.

11 This case has applications outside the United States and No Child Left Behind. Many countries in Europe are concerned with the educational performance of subgroups of children such as poor children or children of immigrants. 
Intrinsic rewards are more directly tied to a bureaucrat's identity. If the arguments are correct about social origins being the source of many values, then taking on a representative role supports the bureaucrat's own values and provides some intrinsic motivation. This motivation might be especially important in organizations that are designed to help clientele by delivering services to them. One of the major empirical distinctions between public and private employees is an altruistic orientation termed "public service motivation," defined "as an individual's predisposition to respond to motives grounded primarily or uniquely in public institutions" (Perry 1996, 6). One key component of public service motivation is compassion, a concern for people in distress and a recognition that people are dependent on each other. Another component deals with social justice which is directly linked to assisting the disadvantaged (Perry 1996). Individuals with high levels of public service motivation hold values very consistent with adopting the role of the representative and, thus, AR (Hypothesis H4). ${ }^{12} \mathrm{AR}$, as a result, can therefore generate intrinsic motivation for individual bureaucrats.

\section{Who Do Bureaucrats Decide to Represent?}

A bureaucrat who adopts the role of a representative likely has myriad options where representation is possible. The demand for AR among clientele is likely greater than the potential supply among bureaucrats. The transactions' costs of representation, as well as the risk of doing so, should depress the supply of AR even further. Because the representative has limited time for representational activities, the potential representative faces several decisions. The representative could attempt to try to represent all cases. In such cases, there is a strong likelihood that the efforts of the representative would be spread too thinly and that many cases of AR would not produce the intended benefits. The decision of the representative facing excessive demand is similar to that of a combat physician performing triage by sorting casualties into a group that will survive without immediate medical attention, a group that will survive if they get immediate medical attention, and a group that will not survive whether or not they get immediate medical attention. The optimal use of the combat physician's efforts in such cases is to focus on the middle group where the intervention is most likely to matter.

Extending this discussion to bureaucratic representation, a university teacher adopting the role of a

12 The idea of linking public service motivation to representative bureaucracy was suggested to me by Norma Riccucci in a personal communication about a manuscript she was planning to write. She should get credit for this insight. representative faces a similar problem. The professor has many avenues of representation available from individual mentoring of students to seeking to change university policies (on admissions or campus climate) to offering diverse views on decision-making. If the professor opts to represent via individual actions with students, there are many students and limited amounts of time that can be devoted to representation (remember the representative also has other duties in the organization). Representation will require time spent with the student in mentoring and providing assistance. In some cases the student will be able to take advantage of this extra assistance and graduate; in other cases, the student is too far behind and unlikely to be able to finish the year let alone graduate, and in other cases, the student will do well without any assistance from the professor. ${ }^{13}$

Given the university professor likely still faces far more possible students than available time, how does the professor decide to allocate representation activities? Four possible decision rules come to mind. First, the coproduction decision rule would be to invest in those cases where the student will provide the most effort, which essentially recognizes that representatives/mentors only contribute at the margins (Hypothesis H5). The client is the one who makes the most difference in the outcome. The advantage of the coproduction rule is that it is likely generalizable to other organizations where coproduction plays a role (welfare to work, law enforcement, etc.).

Second, the allocation of representational effort might be a function of the other values held by the bureaucrat (Hypothesis H6). Returning to our university professor example, such a professor might spend more representation time on students interested in careers in the public service rather than in business (or vice versa depending on the professor). Similarly, a professor might be more interested in students who want to seek graduate degrees in the field than those interested in attending law school.

Third, the bureaucrat might allocate representational time according to the match of identities (Hypothesis H7). Because everyone has multiple identities (see below), clients can match bureaucrats on zero, one, two, three, four or more identities. It is quite possible that an African-American female bureaucrat from a poor family could be more interested in assisting individuals who match up on all three of these identities than those who match up on one or two. The matchup of identities is probably just a more

13 Let me make a normative clarification. By engaging in triage, I am not contending that the bureaucrat is in some cases not going to perform the duties that the organization requires, only that in taking extra effort beyond the normal duties that representation requires, the need to set priorities comes into play. 
complex version of a simpler variable, the salience of the identities to the bureaucrat. A Latino bureaucrat, as an example, with a strong pan-Latino identity should be more likely to act as a representative than a Latino bureaucrat lacking such an identity, all other things being equal.

Fourth, the bureaucrat might weigh the level of risk in engaging in AR with the potential personal benefits. As an example, just as a traffic cop is more likely to give a motorist a warning if the speed limit was exceeded by $5 \mathrm{mph}$ than if the speed limit was exceeded by $40 \mathrm{mph}$, a bureaucrat should be more willing to represent if the degree of deviation from organizational procedures is small rather than if it is large (Hypothesis H8). The contrast between the degree of deviation or discretion and the benefits gained could also come into play.

These four reasons to represent rely on a subjective assessment of benefits and costs, but we know little about the motivations of individual bureaucrats in such cases. Bureaucrats might even look for the most difficult cases because they have some identity linkage (working with drug addiction) or some personal values (Hypothesis H9). There clearly are teachers who focus on preventing dropouts rather than focusing on potentially college-bound students, and many public programs address such severe problems as child abuse, homelessness, or drug addiction where modest improvements in the situation might make a major difference in someone's life.

\section{Who Represents?}

The question of when does a bureaucrat represent suggests that not all bureaucrats engage in representative behavior (or they do not do so all of the time). Selden's (1997) seminal contribution to the literature was to specify that an intermediate step was to take on the role of a representative, something that in terms of race was correlated with the race of the bureaucrat but not perfectly so. Some minorities did not see their role as representing other minorities whereas some nonminorities perceived their role as representing minorities (see also Bradbury and Kellough 2008). So the natural extension to the question of when do bureaucrats represent is which bureaucrats represent?

The previous section on when representation is likely also applies who decides to represent. Bureaucrats are more likely to represent if (1) they see positive coproduction possibilities from the client, (2) the actions are consistent with the bureaucrat's own values, (3) the salience of the identity or identities shared with the client is high, and (4) the potential benefits (either intrinsic or extrinsic) outweigh the costs of representation. To these four reasons for mobilizing bureaucratic representation, three additional hypotheses appear likely that also relate to the burden that representation might place on the bureaucrat over and above the bureaucrat's organizational duties.

First, if bureaucrats weigh the costs and benefits of representation, then the degree to which the bureaucrat possesses slack resources should be positively correlated with representation (Hypothesis H10). Slack resources reduce the risk of representation because the bureaucrat can perform all required functions and still have additional time/resources to engage in representation (Carroll 2017). Second, some bureaucrats will be more productive than others. A bureaucrat who is more efficient at the tasks assigned by the organization, as a result, is also a bureaucrat who likely has the time and energy to devote to representation. If representational actions somehow detract from what the organization is doing, it is also likely that the more productive bureaucrat will be forgiven for any such transgressions (Hypothesis H11). Third, related to the protections likely to come into play for the productive bureaucrat, job security may be related to representation since it lowers the potential costs of representation if the organization does not want the bureaucrat to represent (Hypothesis 12). ${ }^{14}$

Bureaucratic representation might also enhanced by some organizational pathologies that generate suboptimal results for the organization. Although this argument is highly speculative, let us assume an organization that has a glass ceiling where women's access to management positions is circumscribed. The argument here is not concerned if the limited number of women in management positions results from discrimination or if it reflects preferences by women to not move into management. Such an organization is likely to have more talent than optimal at the production or street level and less talent than optimal at the managerial level. If the above logic is correct that bureaucrats who are more efficient and effective are more likely to represent, then glass ceiling organizations should have higher levels of representation both because individuals at the street-level will have the time (as a result of being over skilled) for representation and because the more modest levels of managerial talent will make close monitoring difficult (Hypothesis H13). This logic is consistent with Keiser et al.'s (2012) empirical finding that women teachers have a greater influence on girls' math scores and other indicators of performance when women comprise a smaller portion of the school's managers. Although this argument was presented in the context of glass ceilings, it applies to

\footnotetext{
14 Job security might be another reason why Roch and Pitts (2012) find that bureaucratic representation occurs in public schools and not in private schools. They present a strong argument that the differences result from differences in values, but public school teachers also have greater job security.
} 
any organization and any identity where individuals (with discretion) with that identity are clustered at the bottom of an organization.

\section{Contextual and Structural issues in Representative Bureaucracy}

Three major factors hypothesized to affect the ability of a bureaucracy to translate PR into AR are the critical mass of bureaucrats, intersectional influences on the bureaucrats, and the transition from minority to majority status. Of these much attention has focused on the critical mass question (although with problematic modeling), intersectionality is only starting to get attention, and the transition from minority to majority status has not been addressed.

\section{Implications of Critical Mass}

As noted above, not all cases of PR are associated with evidence of AR. In the private sector, this led Rosabeth Moss Kanter (1993) to postulate that women needed to attain a critical mass of $15 \%$ of the organization before changes in bureaucratic outcomes would be manifest. Although Kanter presented her $15 \%$ criteria based on a theoretical argument linked to gender, the hypothesis concerning a critical mass is widely cited and frequently investigated, especially in the literature on legislative representation. The empirical evidence for a critical mass, however, is relatively mixed in representative bureaucracy. For street-level bureaucrats in education, no critical mass is needed (Meier 1993; Meier and Stewart 1992); the passive to active translation by teachers is present even with small percentages in terms of student learning or education-related outcomes. Similar findings hold in police and sexual assaults, EEOC bureaucrats (Hindera 1993), the Farmer's Home Administration (Selden 1997), etc. At the managerial level, the evidence is stronger for a critical mass; however, the critical mass appears to be closer to $25 \%$ than $15 \%$ for minorities (Meier 1993; Meier and Stewart 1992; but see Keiser et al. 2002 which specifically rejects a critical mass hypothesis for women administrators). Atkins and Wilkins (2013) also report a critical mass for the impact of African-American teachers on teen pregnancy rates in Georgia public schools that is well above $15 \%$.

Determining whether or not a critical mass is required for the translation of $\mathrm{PR}$ into $\mathrm{AR}$ requires some methodological theorizing in part because there are several alternative explanations for null results other than the absence of a critical mass. The base theory would suggest unsalient identities or a lack of discretion as possible explanations whereas the more recent contextual theories would posit that either the internal or external context of the organization created pressures that minimized the ability of passive representatives to influence organizational outputs.

Theoretically, let us assume a critical mass threshold of $Z$, this can be operationalized as a dummy variable with the value of 0 if the PR level is less than $Z$ and equal to 1 if the representation level is above $Z$. This creates a hypothesized relationship that resembles a hockey stick as in figure 3. Because the logic of a critical mass is that PR leads to AR only above the critical threshold of $\mathrm{Z}$, one might be tempted to test for this relationship with the following equation:

$$
\mathrm{AR}=\beta_{1} \mathrm{PR} * \mathrm{Z}+\varepsilon
$$

This formula, however, assumes that the relationship fits a curve such as that in figure 3 rather than subjecting the relationship to an empirical test. The problem is that this equation will also produce strong empirical results if the relationship fits the strictly linear pattern in figure 1 depending on the value of the threshold $(Z)$. Separate from the problem of concluding a threshold exists when one does not, equation (5) violates Occam's Razor, the principle that of two equally possible explanations, the simpler one (equation 1 ) is preferred. The solution is to determine if the addition of a threshold to an existing model results in an improved level of prediction over a model lacking the threshold. ${ }^{15}$

To statistically model thresholds, it is important to recognize that three different threshold impacts might occur. The hockey stick pattern in figure 3 holds that PR has no impact at all until a threshold is reached; and after that point, there is a positive linear relationship between AR and PR. The impact of a threshold could also be a step function as in figure 4 where PR has no impact below a threshold and has a constant impact above the threshold. This type of threshold exists in majoritarian institutions with strong group discipline (i.e., in legislatures with strong party discipline, one has no influence until the group attains majority status).

In estimation terms, figure 3 depicts a change in slope model (the slope does not have to be zero before the threshold to have a threshold effect); figure 4 shows a change in intercept model (again, the slope need not be zero before the threshold, only that the pre-threshold slope is equal to the post-threshold slope). It is also possible that a threshold might change

15 The figures assume that below the threshold that there is no relationship between PR and AR. Below the threshold, the relationship could be negative; if so, equation (3) would better fit these data. This could happen if token minority employees tried to conform to then norms of the organization in a zealous manner. 


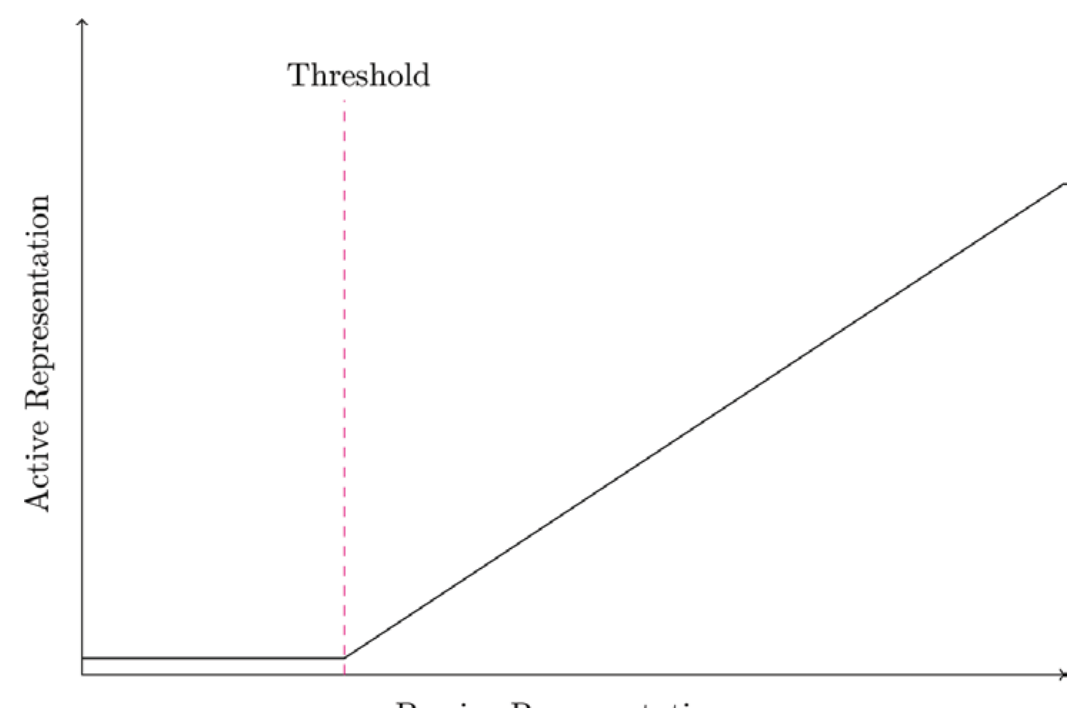

Passive Representation

Figure 3. Graph of Critical Mass as it Affects the Translation of Passive to Active Representation:The Change in Slope Hypothesis.

both the slope and the intercept as in figure 5. The logic of thresholds suggests that the appropriate way to test for them is to allow for the possibility of both a slope and an intercept change and statistically determine if they exist by using the following equation (Modeling Recommendation M3; Hypothesis H13):

$$
\mathrm{AR}=\beta_{1} \mathrm{PR}+\beta_{2} \mathrm{Z}+\beta_{3} \mathrm{P} * \mathrm{RZ}+\varepsilon
$$

The first term in the model estimates the representation relationship below the threshold and may or may not be zero. The second term estimates the step function, and the third term estimates the change in slope function. So the hockey stick pattern in figure 3 would yield insignificant coefficients for the first term $\left(\beta_{1}=0\right)$ and the second term $\left(\beta_{2}=0\right)$ and a positive slope for the third term $\left(\beta_{3}>0\right)$. For a pattern like that in figure 4 , the second term would be statistically significant $\left(\beta_{2}>0\right)$ and the third term would be zero $\left(\beta_{3}=0\right)$; the first term could take any value depending on whether there was any relationship before the threshold. If both the second and third terms are significant, one has a threshold that both changes the intercept of the line and its slope. If both the second and the third term in the equation are insignificant, that is, take values of zero, the equation reduces to the linear relationship found in figure 1 and equation (1).

The statistical tests for threshold effects beg one important question, exactly where is the threshold? Is it at $15 \%$ as Kanter contends or at $25 \%$ as several of the empirical estimates in education find (Meier 1993; Meier and Stewart 1992) or at 50\% (the proportion needed to make decisions in a majoritarian institution) or at some other percentage? One option is to start with a theoretically specified threshold and then conduct sensitivity analysis to determine the optimal threshold for predictive purposes. ${ }^{16}$ A second option used in the literature (Meier 1993) is to slightly mis-specify the threshold model in equation (6) by operationalizing equation (3) but looking for a different pattern of relationship than diminishing marginal returns:

$$
\mathrm{AR}=\beta_{1} \mathrm{PR}+\beta_{2} \mathrm{PR}^{2}+\varepsilon
$$

In this case a threshold might be estimated if the first term is negative and the second term is positive (a U-shaped relationship) with the first derivative of this equation indicating where the relationship changes from negative to positive, or substantively where PR is associated with positive gains in AR (Meier, Wrinkle, and Polinard 1999).

\section{Considering Intersectionality}

One of the key problems in social science involves the concept of intersectionality (Hancock 2007), and representative bureaucracy is no exception to this generalization (Bearfield 2009). Bureaucrats have multiple identities, and the intersection of each of them (not the least of which is the identity as a bureaucrat) are potentially relevant for the study of representative bureaucracy. This section, however, will focus only on the identities of race and gender to illustrate some difficulties in studying intersectionality, but the logic should apply to most if not all cases with other identities (Gilad and Alon-Barkat 2017, 2018). The question becomes when does a bureaucrat respond in terms of

16 Sensitivity analysis implies multiple tests with the same data and thus violates the basic assumptions of probability as applied to inferential statistics. For that reason, determining the threshold level should be done independently from testing the hypothesis of a threshold (i.e., it would normally require two separate datasets). 


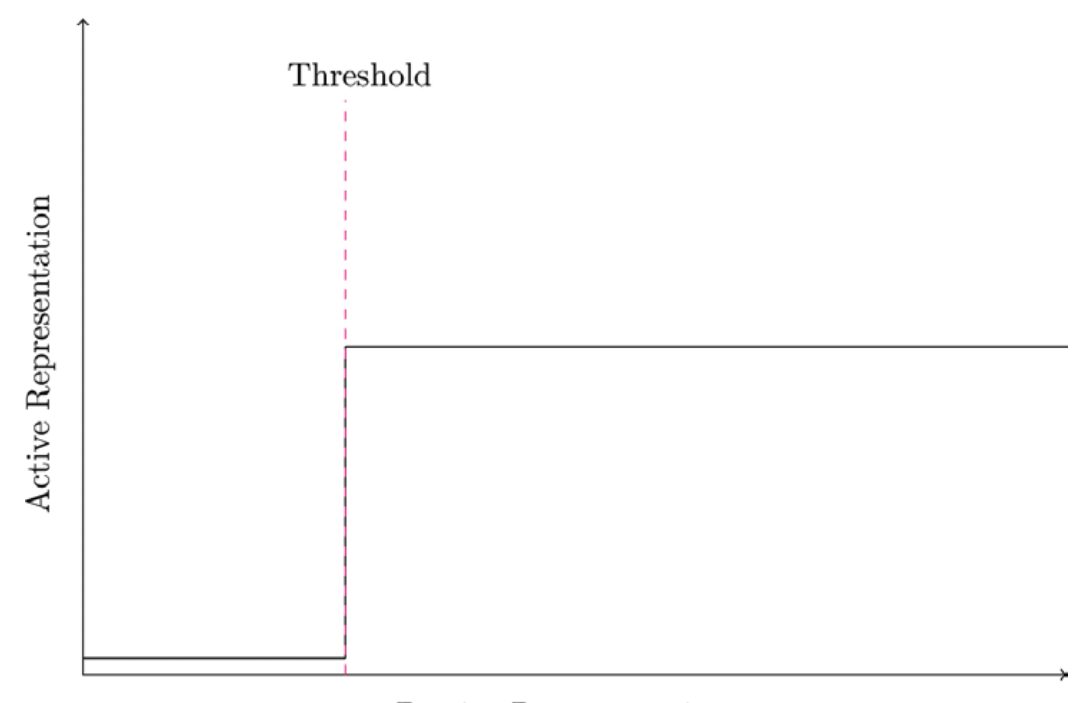

Passive Representation

Figure 4. Critical Mass as a Step Function Linking Passive to Active Representation.

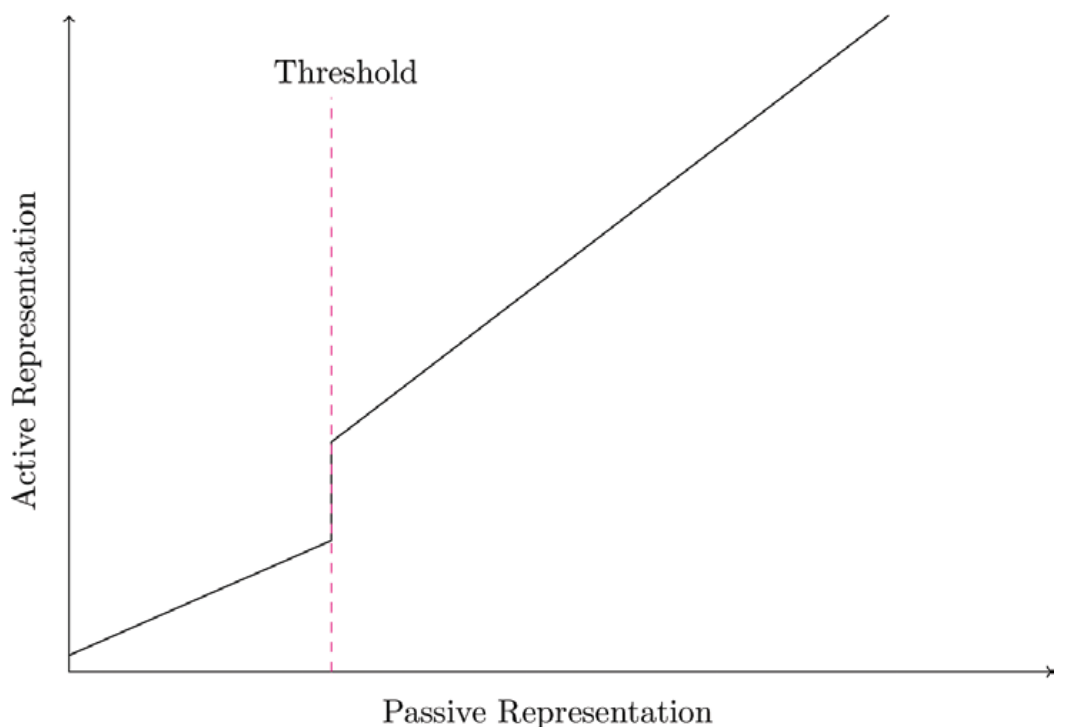

Figure 5. Critical Mass with Both an Intercept and a Slope Change.

gender and/or in terms of race when making organizational decisions. The basic premise of intersectionality is that identities do not aggregate in an additive manner, that is, the impact of being a black female is not the sum of the impact of being female plus the impact of being black (Hancock 2007). Identities can combine such that they can be greater than the sum of their individual parts or less than that sum.

The study of intersectionality in representative bureaucracy generates several methodological issues that need to be clarified, particularly for those examining aggregate data. To illustrate let $\mathrm{F}$ designate a female bureaucrat, $\mathrm{B}$ designate a black bureaucrat, and $\mathrm{BF}$ designate a black female bureaucrat. Whether at the individual or the organizational level, AR is indicated by the following model which allows for the individual identities to matter as well as the combinations (Modeling Recommendation M4):

$$
\mathrm{AR}=\beta_{1} \mathrm{~F}+\beta_{2} \mathrm{~B}+\beta_{3} \mathrm{BF}+\varepsilon
$$

To determine if intersectionality matters in representation, the third term $\left(\beta_{3}\right)$ needs to be statistically different from zero. That would suggest that the combination of identities provides some explanation over and above the individual parts. Note that this test does not specify a direction. If $\beta_{3}$ is significant in the same direction as $\beta_{1}$ and $\beta_{2}$, the intersectionality matters more than just the individual identities. That could take either of the following two patterns: 


$$
\beta_{1}, \beta_{2}, \beta_{3}>0
$$

or

$$
\beta_{1}, \beta_{2}, \beta_{3}<0
$$

If $\beta_{3}$ is significant in a different direction from $\beta_{1}$ and $\beta_{2}$, it means that the intersectionality relationship reduces the importance of the individual identities, that is, together they are less than the sum of their parts. This can occur also in two ways as follows:

$$
\beta_{1}, \beta_{2},>0 \text { and } \beta_{3}<0
$$

or

$$
\beta_{1}, \beta_{2},<0 \text { and } \beta_{3}>0
$$

When not all coefficients are in the same direction, understanding the impact of the individual identities and the intersectionality often requires graphing the relationship to show the marginal effects of one variable at varying levels of the other variable (see Branton et al. 2015 for an illustration). The same advice holds when the two identity coefficients are of opposite signs and significant, and the intersectionality coefficient is also significant (and sometimes when it is not since graphing the relationship could reveal a significant impact at some range of the data). The assessment of intersectionality is further complicated because various identities can be a positive factor in some situations and a negative factor in others. In terms of gender, being male is an advantage in areas such as employment (Budig 2002), but it is a clear disadvantage in terms of contact with the criminal justice system (Steffensmeier, Ulmer, and Kramer 1998). This change means that although one would expect that AfricanAmerican women would be at a double disadvantage, in some policy areas such as education they are relatively advantaged compared to African-American men (Bailey and Dynarski 2011).

The use of aggregate data to examine questions of intersectionality faces another methodological question: Government sources often do not provide data by intersectional categories. Public data on government employment is generally reported by race or by gender but not by the various race and gender combinations. That means rather than estimating the intersectional relationship by equation (7):

$$
\mathrm{AR}=\beta_{1} \mathrm{~F}+\beta_{2} \mathrm{~B}+\beta_{3} \mathrm{BF}+\varepsilon
$$

The analyst estimates question (12) with an interaction of black employees (B) and female employees $(\mathrm{F})$ :

$$
\mathrm{AR}=\beta_{1} \mathrm{~F}+\beta_{2} \mathrm{~B}+\beta_{3} \mathrm{~B} * \mathrm{~F}+\varepsilon
$$

Equation (12) has the potential for error in estimating the intersectionality impact to the degree that the gender composition of the employees differs across the racial groups. It could over or underestimate any intersectionality impact.

The final complication involving intersectionality is that it is tempting to focus on the interaction of some identities such as race and gender and not consider the other potential intersectional relationships. Recall the earlier contention that all bureaucrats had multiple identities; an incomplete list might include gender, race, class, religion, profession, government employee, agency employee, and so on. The above discussion illustrated the complications of intersectionality with only two identities. With three identities the number of terms in equation (7) increases to seven (each combination of two plus the combination of three); four identities generate 14 possible relationships. Clearly, intersectionalities can quickly become too complex or too data demanding to be estimated empirically. This also suggests that studies of intersectionality on groups of nonbureaucrats might not be generalizable to bureaucrats or that studies from agency A might not generalize to agency B. Clearly additional theoretical work is needed to bring some parsimony to what appears to be an intractable empirical problem.

The discussion of intersectionality thus far has really only considered the supply of intersectionality, that is, the intersectionality of the bureaucrats. Earlier discussions about who represents and who is represented suggested there is also a demand for intersectionality, that is, the intersectional position of the clientele will also matter (Hypothesis 14). The distinction between the supply side and the demand side of intersectionality is important because much of the work (focused on legislatures, see Reingold and Smith 2012) deals with the intersectionality of the representative but does not consider the intersectionality of the represented. Such studies demonstrate how race and gender together mean more for representatives' behaviors than either separately, but that is only one of the interesting questions. An equally interesting question is whether bureaucrats influence clientele outcomes based on the intersectional identities of the clientele or the matchup of the bureaucratic and clientele identities (Grissom, Nicholson-Crotty, and Keiser 2012; Grissom, Rodriguez, and Kern 2017; Nicholson-Crotty et al. 2016; Pitts 2005).

\section{What Happens When Minorities Become the Majority?}

The study of representative bureaucracy appears to be relatively time invariant, that is, the issue is examined at single points in time. Even when done with panel data, the analysis usually does not deal with the 
dynamics of the relationship between passive and AR (e.g., Meier, Wrinkle, and Polinard 1999), that is, the analysis does not examine how relationships change over time. Clearly patterns of PR are not static but change over time in response to changes in policy or changes in the environment (Hong 2017a; Meier, Pennington, and Eller 2005; Meier and Smith 1994). ${ }^{17}$ If PR leads to AR, then one would expect changes in PR to have consequences. Two aspects of the theory of representative bureaucracy make it an interesting scholarly domain; it concerns disadvantaged groups and those groups are in a minority in the organization (and likely politically). Over time or across space, however, both of these factors can change; disadvantaged groups can be treated equitably, and minority groups can become majorities (both as clientele and more importantly in the bureaucracy). The case of disadvantaged groups attaining equity in treatment was addressed above; this section will examine what happens when a numerical minority becomes a majority within an organization.

The lack of studies on organizations where disadvantaged minorities become a majority in the organization is surprising given the visible existence of these organizations (the US EEOC at the federal level, numerous school districts and cities also have black or Latino majorities). The logic of a critical mass clearly implies that when a group achieves majority status in a bureaucracy that the linkage between passive and AR will increase. At the same time, bureaucracies are open systems and need to extract resources from the environment to survive. Given the general differences in economic and political resources among racial groups, majority-minority bureaucracies might have an incentive to retain the loyalty and commitment of the "new minority" group. If so, then one might expect that the increase in the relationship between passive and AR might be subject to diminishing marginal returns after the disadvantaged group becomes the majority (Hypothesis 15). If combined with a threshold effect, the relationship between PR and AR might well form an S-curve, where little representation occurs until a critical mass is reached, then a rapid increase in representation occurs which at some point levels off due to pressures to retain the "new minority" clientele for reasons of economic and political support.

17 Hong's (2017) longitudinal study of Welsh and English policing is an exception in that it explicitly incorporates a time dimension. That study demonstrates that there is a time lag between changes in $P R$ and changes in AR. It also shows that there is no drop in AR as representation increases, what Hong terms the "diversity fatigue" hypothesis.

\section{Conclusions and Paths Forward}

This essay on representative bureaucracy addressed a wide variety of issues and presented some new ideas in regard to the basic concepts of representative bureaucracy (identity, salience, etc.), four methodological recommendations for the research, 15 new hypotheses for testing, and some theoretical ideas. Since this theoretical essay covered a wide variety of topics, a recapitulation of the main points is in order. The objective of the essay is to stimulate new discussions concerning representative bureaucracy and encourage empirical and normative investigations of the questions that have been raised.

First, thinking of the relationship between PR and $\mathrm{AR}$ as an interactive relationship with other variables is a useful exercise (M1, equation 2). Not all cases of PR result in AR (Watkins-Hayes 2011; Wilkins and Williams 2009); in fact, the literature now rarely asks if it matters but under what conditions it matters. The literature has been strongly guided by theories that start with the concepts of discretion and identities and incorporate institutional factors such as hierarchy, critical mass, centralization, and other organizational or political factors. Comparative and contextual theories of representative bureaucracy (Groeneveld et al. 2015; Meier and Morton 2015) present their ideas in this interactive logic, and many of the ideas in this essay followed that example. The advantage of thinking in this manner is that it provides some exact statistical tests for various hypotheses and presents new theoretical insights in a parsimonious manner.

Second, the linkage between representative bureaucracy and outcomes that benefit the disadvantaged is important for both normative and empirical reasons. Representative bureaucracy can be proposed as a solution to the problem of bureaucracy and democracy because bureaucrats represent individuals who are lacking representation in other ways (Long 1952; Mosher 1968; Riccucci and Saidel 1997). To those who challenge the legitimacy of bureaucratic representation, the response should be that all bureaucracies represent (H1). Generally, they represent the interests of the powerful, often as expressed in legislative intent and agency missions. If political institutions provided an equitable representation of the disadvantaged, then perhaps the need for bureaucratic representation would disappear. The study of representative bureaucracy is compelling for this very reason; representative bureaucracies deviate from their normal patterns of action and represent individuals who are under represented in the political and policy process. That bureaucracies do this when they are not designed to aggregate interests as are other representative institutions (legislatures, interest groups) is why the study of 
representative bureaucracy is an interesting normative and empirical endeavor. ${ }^{18}$

Third and related to the second point of representing the disadvantaged, this essay raised the issue of whether the goal of a representative bureaucracy (in the aggregate sense) was representation or equity. Noting some anomalies in the literature where the representational influence of bureaucracy tapered off, an argument was presented that bureaucratic representation might be seeking equity for the disadvantaged not a bias in favor of the represented. A methodology for testing this hypothesis and some places where it might be found were presented (M2, H2). Empirical tests of this argument have major normative implications for the debates on representative bureaucracy. If representative bureaucracies' ultimate goal is equity, then the contention that representative bureaucracies are biased is more difficult to defend.

The fourth, fifth and sixth points addressed representative bureaucracy as an individual level behavior. Fourth, given the pressures in most organizations, an important question is why bureaucrats are willing to undergo the risks entailed in adopting the role of the representative? This essay argued that bureaucrats could adopt this role in response to both extrinsic and intrinsic motivations. Representative bureaucracies can sometimes improve overall performance; and, therefore, some rational organizations will seek out PR and reward AR (or at least the outcomes of AR [H3a, $\mathrm{H} 3 \mathrm{~b}, \mathrm{H} 3 \mathrm{c}])$. In situations where bureaucracies do not provide such extrinsic rewards, intrinsic rewards such as public service motivation or the ability to assist individuals with shared identities encourage bureaucrats to engage in representation $(\mathrm{H} 4)$.

Fifth, clearly the demand for representative bureaucracy among clients far exceeds the supply of AR in the overwhelming proportion of bureaucracies. A representative bureaucrat cannot help every individual who shares his or her identities. This essay suggested that bureaucratic representatives engage in a process of triage to determine how to allocate their representational effort. This triage might include the number of shared identities (H7), the likelihood of client coproduction (H5), the level of risk (H8), the degree of disadvantage (H9), or other values held by the bureaucrat (H6).

18 The relationship between political representation and bureaucratic representation is greatly understudied. Meier and Rutherford (2017) argue that the interaction of political and bureaucratic representation could be either positive (if they augment each other and provide support for greater efforts) or negative (if one institution decides to let the other handle the representation function). They also apply this notion to representation at different levels in the bureaucracy. That study involved political and bureaucratic representation that was consistent with each other (both cases involved African-American representation); another interesting case is when political and bureaucratic representation push in different directions.
At the present time, we know little about the decision process of the bureaucratic representative, and studying this process could greatly inform the literature on representative bureaucracy.

Sixth, determining who adopts the role of a representative is still in its infancy (Bradbury and Kellough 2008; Selden 1997). The obvious choice is individuals who share identities, but not all individuals with a given identity decide to represent, and some individuals lacking the relevant identity do. This essay also suggested that having slack resources $(\mathrm{H} 10)$, greater discretion (H12), and even greater efficiency (H11) create the potential for individuals to act as representatives and to resist any organizational pressures to not do so. The essay also proposed that AR might actually be higher in organizations characterized by glass ceilings given that such barriers maldistribute organizational talent (H13).

The seventh, eighth and ninth discussions concerned how to address a set of major issues that affect the linkage between PR and AR. Seventh, scholars of representative bureaucracy need to more seriously engage the notion of a critical mass if it is to remain part of the theoretical considerations. Research seeking to find a critical mass in representative bureaucracy at times finds it (Atkins and Wilkins 2013) and at times finds that a critical mass is not needed (Meier and Stewart 1992). Part of the problem might be in the unsystematic way in which critical masses are assessed, and this essay provided some statistical ways (using the logic of interactions) to separate out when a critical mass exists distinct from a normal pattern of representation (or distinct from the absence of representation [M3]). To be a valued aspect of the representative bureaucracy literature, the field needs new theory on why a critical mass is required in some organizations or at some levels of the organization and not others. The existing literatures both in representative bureaucracy and in the broader representative literature are generally silent on this important question. What is clear in the literature is that the idea of a critical mass at $15 \%$ of the organization has little empirical support in the representative bureaucracy literature.

Eighth, the complexity of dealing with the multiple intersectionalities of the bureaucrat is virtually intractable. The interaction approach advocated here provides insight on relatively simple combinations of two identities and possibly three identities (M4). The statistical complexities that result as identities multiply suggest that progress in this area requires more theoretical effort and likely the building of qualitative case studies to generate data for the theorizing. That does not mean that progress cannot be made on the combination of a modest number of identities where the data exist (H14), only that such studies 
are a first (and likely necessary) step to understanding the full implications of multiple identities on bureaucratic behavior (including the behavior of the representative).

Ninth, representative bureaucracy is a field concerned with disadvantaged groups, and these groups are often a minority of the population. The combination, given that population minorities tend to be political minorities, ${ }^{19}$ is frequently what makes representative bureaucracy an interesting political and administrative phenomena. At the same time, it is important to recognize historically that populations shift, minorities become majorities, and disadvantaged groups sometimes become advantaged. How the linkage between $\mathrm{PR}$ and AR evolves when such change occurs is important for extensions of the theory. Does the salience of representation decline as the new majority exerts control over the bureaucracy (H15)? Does the new majority seek ways to retain the cooperation and support of the old majority? We have numerous cases of womenor minority-dominated bureaucracies at the local and state level in the United States (Guy 1992) that would serve as places to test these ideas.

This theoretical logic and discussion do not exhaust the issues facing scholars of representative bureaucracy, and others (Groeneveld et al. 2015; Groeneveld and Van de Walle 2010; Meier and Morton 2015) have pressed different issues in comparative contexts. Similar issues occur on the symbolic aspects of representative bureaucracy (Riccucci and Van Ryzin 2017). The need to expand the range of organizations studied is also important. The overwhelming majority of studies have examined street-level bureaucracies, in part, because such organizations vest significant discretion in bureaucrats and contact with citizens reinforces the salience of identities such as race and gender. Data available likely also plays a significant role selecting cases to study. The original theory (Mosher 1968) and the initial applications dealing with attitudes rather than behaviors (Meier and Nigro 1976) did not limit the theory to street-level bureaucracies (see also the chapters in Schröter, von Maravic, and Peters (2015) that apply the theory to numerous different organizations cross-nationally). If at its core, representative bureaucracy involves bureaucrats acting on personal values originating from social origins, then one might expect to find the behavior in a wide variety of organizations. Minority bureaucrats in environmental protection agencies, for example, should be well aware of the environmental justice literature and the impact

19 Internationally there are many cases where population minorities are political majorities, that is, they are the ruling group (see the discussion in the international relations literature on ethnic-linguistic fractionalization, Cederman and Girardin 2007). of pollution and its regulation on poor and minority neighborhoods (Ringquist 2005). Regulations from the Occupational Safety and Health Administration have clear social class elements that are reflected in the disputes between business and labor (Jordana and Levi-Faur 2004). All central bankers are likely to be aware that their policies on inflation have obvious consequences for debtors and creditors and thus social classes. Although there is little empirical representative bureaucracy literature on non-street-level bureaucracies, the hypotheses and arguments noted below are likely to be applicable to many such agencies. Theorizing about these specific types of agencies is an important avenue for future research. Finally, combining all the partial models of representation expressed in this essay into a single, parsimonious model remains a daunting task. What the discussion does is contribute to the opportunities for new research in the area of representative bureaucracy; what we do not know can occupy scores of scholars for many years.

\section{References}

Akram, Sadiya. 2017. Representative bureaucracy and unconscious bias: Exploring the unconscious dimension of active representation. Public Administration 96:119-133. doi:10.1111/padm.12376

Andrews, Rhys, Rachel Ashworth, and Kenneth J. Meier. 2014. Representative bureaucracy and fire service performance. International Public Management Journal 17 (1): 1-24.

Andrews, Rhys, and Karen Johnston Miller. 2013. Representative bureaucracy, gender, and policing: The case of domestic violence arrests in England. Public Administration 91:998-1014.

Ashikali, Tanachia, and Sandra Groeneveld. 2015. Diversity management for all? An empirical analysis of diversity management outcomes across groups. Personnel Review 44:757-80.

Atkins, Daniele N., and Vicky M. Wilkins. 2013. Going beyond reading, writing, and arithmetic: The effects of teacher representation on teen pregnancy Rates. Journal of Public Administration Research and Theory 23:771-90.

Bailey, Martha J., and Susan M. Dynarski. 2011. Gains and gaps: Changing inequality in US college entry and completion. No. w17633. Washington, DC: National Bureau of Economic Research.

Bearfield, Domonic A. 2009. Equity at the intersection: Public administration and the study of gender. Public Administration Review 69:383-6.

Bradbury, Mark D., and J. Edward Kellough. 2008. Representative bureaucracy: Exploring the potential for active representation in local government. Journal of Public Administration Research and Theory 18:697-714.

Branton, Regina., Valerie Martinez-Ebers, Tony E. Carey, and Tetsui Matsubayashi. 2015. Social protest and policy attitudes: The case of the 2006 immigrant rallies. American Journal of Political Science 59:390-402.

Budig, Michelle J. 2002. Male advantage and the gender composition of jobs. Social Problems 49:258-77.

Calderon, M. Apolonia. 2018. Hablas espanol? The role of language congruence as representative bureaucracy. Unpublished PhD Dissertation. College Station, TX: Texas A\&M Univ.

Carroll, Kristen M. 2017. When representatives work: The influence of local context on minority representation. Unpublished PhD Dissertation. College Station TX: Department of Political Science, Texas A\&M Univ.

Cederman, Lars-Erik, and Luc Girardin. 2007. Beyond fractionalization: Mapping ethnicity onto nationalist insurgencies. American Political Science Review 101:173-85. 
Clinton, Joshua D., and David E. Lewis. 2007. Expert opinion, agency characteristics, and agency preferences. Political Analysis 16:3-20.

Dal Bó, Ernesto. 2006. Regulatory capture: A review. Oxford Review of Economic Policy 22:203-25.

Downs, Anthony. 1967. Inside bureaucracy. Boston, MA: Little-Brown.

Easton, David. 1965. A systems analysis of political life. New York, NY: Wiley.

Epp, Charles R., Steven Maynard-Moody, and Donald P. Haider-Markel. 2014. Pulled over: How police stops define race and citizenship. Chicago, IL: Univ. Chicago Press.

Frederickson, H. George. 1990. Public administration and social equity. Public Administration Review 50:228-37.

Gade, Daniel M., and Vicky M. Wilkins. 2013. Where did you serve? veteran identity, representative bureaucracy, and vocational rehabilitation. Journal of Public Administration Research and Theory 23:267-88.

Gailmard, Sean, and John W. Patty. 2007. Slackers and Zealots: Civil service, policy discretion, and bureaucratic expertise. American Journal of Political Science 51:873-89.

Gilad, Sharon, and Saar Alon-Barkat. 2018. Enhancing democracy via bureaucracy: Senior managers' social identities and motivation for policy change. Governance 31:359-380. doi:10.1111/gove.12300/full

Grissom, Jason A., Jill Nicholson-Crotty, and Lael Keiser. 2012. Does my boss's gender matter? Explaining job satisfaction and employee turnover in the public sector. Journal of Public Administration Research and Theory 22:649-73.

Grissom, Jason A., Luis A. Rodriguez, and Emily C. Kern. 2017. Teacher and principal diversity and the representation of students of color in gifted programs. The Elementary School Journal 117:396-422.

Groeneveld, Sandra, Kenneth Meier, Eckhard Schroter, and Rhys Andrews. 2015. Representative bureaucracy and public service performance: Where why and how does representativeness work. Presented at the Annual Conference of European Group for Public Administration, Toulouse, France.

Groeneveld, Sandra, and Steven Van de Walle. 2010. A contingency approach to representative bureaucracy: Power, equal opportunities and diversity. International Review of Administrative Sciences 76:239-58.

Guy, Mary Ellen, ed. 1992. Women and men of the states: Public administrators at the state level. Armonk, NY: ME Sharpe Incorporated.

Hammond, Thomas H., and Paul A. Thomas. 1989. The impossibility of a neutral hierarchy. Journal of Law, Economics, \& Organization 5:155-84

Hancock, Ange-Marie. 2007. When multiplication doesn't equal quick addition: Examining intersectionality as a research paradigm. Perspectives on Politics 5:63-79.

Hawes, Daniel P. 2013. Representation, salience, and responsiveness to Latino student performance. Journal of Latinos and Education 12:87-107.

Hindera, John J. 1993. Representative bureaucracy: Further evidence of active representation in the EEOC district offices. Journal of Public Administration Research and Theory 3:415-29.

Hong, Sounman. 2016. Representative bureaucracy, organizational integrity, and citizen coproduction: Does an increase in police ethnic representativeness reduce crime? Journal of Policy Analysis and Management 35:11-33.

- 2017a. Black in blue: Racial profiling and representative bureaucracy in policing revisited. Journal of Public Administration Research and Theory 27:547-61.

_ 2017b. "Does increasing ethnic representativeness reduce police misconduct?" Public Administration Review 77:195-205.

Jordana, Jacint, and David Levi-Faur. 2004. The politics of regulation: Institutions and regulatory reforms for the age of governance. Cheltenham, UK: Edward Elgar Publishing.

Kanter, Rosabeth Moss. 1993. Men and women of the corporation. New York, NY: Basic Books.

Katznelson, Ira. 2005. When affirmative action was white: An untold history of racial inequality in twentieth-century America. New York, NY: WW Norton \& Company.

Keiser, Lael R. 2010. Representative bureaucracy. In The Oxford handbook on American Bureaucracy, ed. Robert Durant, 714-37. New York, NY: Oxford Univ. Press.
Keiser, Lael R., and Daniel P. Hawes. 2007. Gender diversity, organizations and policy implementation: The case of school discipline. Paper presented at the annual meeting of the Midwest Political Science Association, Chicago, IL.

Keiser, Lael R., Vicky Wilkins, Kenneth J. Meier, and Catherine Holland. 2002. Lipstick and logarithms: Gender, identity, and representative bureaucracy. American Political Science Review 96:553-65.

Kennedy, Brandy. 2014. Unraveling representative bureaucracy a systematic analysis of the literature. Administration \& Society 46:395-421.

Knight, Jack. 1992. Institutions and social conflict. New York, NY: Cambridge Univ. Press.

LaVeist, Thomas A. 2005. Minority populations and health. San Francisco, CA: Jossey-Bass.

Lee, Jaekyung. 2002. Racial and ethnic achievement gap trends: Reversing the progress toward equity? Educational Researcher 31:3-12.

Lieberman, Robert C. 2001. Shifting the color line: Race and the American welfare state. New York, NY: John Wiley \& Sons.

Lim, Hong-Hai. 2006. Representative bureaucracy: Rethinking substantive effects and active representation. Public Administration Review 66:193-204.

Long, Norton E. 1952. Bureaucracy and constitutionalism. American Political Science Review 46:808-18.

Maantay, Juliana. 2001. Zoning, equity, and public health. American Journal of Public Health 91:1033-41.

Manna, Paul. 2006. Control, Persuasion, and educational accountability: Implementing the no child left behind act. Educational Policy 20:471-94.

-2010. Collision course: Federal education policy meets state and local realities. Washington, DC: CQ Press.

Meier, Kenneth J. 1993. Latinos and representative bureaucracy testing the Thompson and Henderson hypotheses. Journal of Public Administration Research and Theory 3:393-414.

Meier, Kenneth J., and John Bohte. 2003. Span of control and public organizations: Implementing Luther Gulick's research design. Public Administration Review 63:61-70.

Meier, Kenneth J., Warren S. Eller, Robert D. Wrinkle, and J. L. Polinard. 2001. Zen and the art of policy analysis. Journal of Politics 63:616-29.

Meier, Kenneth J., and Daniel P. Hawes. 2009. Ethnic conflict in France: A case for representative bureaucracy? The American Review of Public Administration 39:269-85.

Meier, Kenneth J., and Tabitha S. M. Morton. 2015. Representative bureaucracy in a cross-national context: Politics, identity, structure and discretion. In The politics of representative bureaucracy: Power, legitimacy, performance, ed. Eckhard Schröter, Patrick von Maravic and B. Guy Peters, 94-112. Cheltenham, UK: Edward Elgar.

Meier, Kenneth J., and Jill Nicholson-Crotty. 2006. Gender, representative bureaucracy, and law enforcement: The case of sexual assault. Public Administration Review 66:850-60.

Meier, Kenneth J., and Lloyd G. Nigro. 1976. Representative bureaucracy and policy preferences: A study in the attitudes of federal executives. Public Administration Review 36(4):458-469.

Meier, Kenneth J., Michael S. Pennington, and Warren S. Eller. 2005. Race, sex, and Clarence Thomas: Representation change in the EEOC. Public Administration Review 65:171-9.

Meier, Kenneth J., and Amanda Rutherford. 2017. The politics of AfricanAmerican education: Race, partisanship and educational equity. New York, NY: Cambridge Univ. Press.

Meier, Kenneth J., and Kevin B. Smith. 1994. Representative democracy and representative bureaucracy: Examining the top-down and bottom-up linkages. Social Science Quarterly 75:790-803.

Meier, Kenneth J., and Joseph Stewart. 1992. The impact of representative bureaucracies: Educational systems and public policies. The American Review of Public Administration 22:157-71.

Meier, Kenneth J., Robert D. Wrinkle, and Jerry L. Polinard. 1999. Representative bureaucracy and distributional equity: Addressing the hard question. Journal of Politics 61:1025-39. 
Mosher, Frederick C. 1968. Democracy and the public service. New York, NY: Oxford Univ. Press.

Moynihan, Donald, Pamela Herd, and Hope Harvey. 2015. Administrative burden: learning, psychological, and compliance costs in citizen-state interactions. Journal of Public Administration Research and Theory 25:43-69.

Nicholson-Crotty, Jill, Jason A. Grissom, and Sean Nicholson-Crotty. 2011. Bureaucratic representation, distributional equity, and democratic values in the administration of public programs. Journal of Politics 73:582-96.

Nicholson-Crotty, Sean, Jason A. Grissom, Jill Nicholson-Crotty, and Christopher Redding. 2016. Disentangling the causal mechanisms of representative bureaucracy: Evidence from assignment of students to gifted programs. Journal of Public Administration Research and Theory 26:745-57.

Oberfield, Zachary W. 2014. Becoming bureaucrats: Socialization at the front lines of government service. Philadelphia, PA: Univ. Pennsylvania Press.

Perry, James L. 1996. Measuring public service motivation: An assessment of construct reliability and validity. Journal of Public Administration Research and Theory 6:5-22.

Peters, B. Guy, Eckhard Schröter, and Patrick von Maravic. 2015. Delivering public services in multi-ethnic societies: The challenge of representativeness. In The politics of representative bureaucracy: power, legitimacy, performance, ed. Eckhard Schröter, Patrick von Maravic and B. Guy Peters, 1-23. Cheltenham, UK: Edward Elgar.

Pitts, David W. 2005. Diversity, representation, and performance: Evidence about race and ethnicity in public organizations. Journal of Public Administration Research and Theory 15:615-31.

Reingold, Beth, and Adrienne R. Smith. 2012. Welfare policymaking and intersections of race, ethnicity, and gender in US state legislatures. American Journal of Political Science 56:131-47.

Riccucci, Norma M., and Judith R. Saidel. 1997. The representativeness of state-level bureaucratic leaders: A missing piece of the representative bureaucracy puzzle. Public Administration Review 57:423-30.

Riccucci, Norma M., and Gregg G. Van Ryzin. 2017. Representative bureaucracy: A lever to enhance social equity, coproduction, and democracy. Public Administration Review 77:21-30.

Riccucci, Norma M., Gregg G. Van Ryzin, and Cecilia F. Lavena. 2015. Representative bureaucracy in policing: Does it increase perceived legitimacy? Journal of Public Administration Research and Theory 24:537-51

Riccucci, Norma M., Gregg G. Van Ryzin, and Huafang Li. 2016. Representative bureaucracy and the willingness to coproduce: An experimental study. Public Administration Review 76:121-30.

Ringquist, Evan J. 2005. Assessing evidence of environmental inequities: A meta-analysis. Journal of Policy Analysis and Management 24:223-47.

Roch, Christine H., and David W. Pitts. 2012. Differing effects of representative bureaucracy in charter schools and traditional public schools. The American Review of Public Administration 42:282-302.
Rocha, Rene R., and Daniel P. Hawes. 2009. Racial diversity, representative bureaucracy, and equity in multiracial school districts. Social Science Quarterly 90:326-44.

Romzek, Barbara S., and J. Stephen Hendricks. 1982. Organizational involvement and representative bureaucracy: Can we have it both ways? American Political Science Review 76:75-82.

Rourke, Francis E. 1984. Bureaucracy, politics, and public policy, 3rd ed. Boston, MA: Little, Brown.

Schröter, Eckhard, Patrick von Maravic, and B. Guy Peters. 2015. The politics of representative bureaucracy: Power, legitimacy, performance. Cheltenham, UK: Edward Elgar.

Selden, Sally Coleman. 1997. The promise of the representative bureaucracy: Diversity and responsiveness in a government agency. Armonk, NY: ME Sharpe.

Smith, Amy E., and Karen R. Monaghan. 2013. Some ceilings have more cracks: Representative bureaucracy in federal regulatory agencies. The American Review of Public Administration 43:50-71.

Soss, Joe. 1999. Lessons of welfare: Policy design, political learning, and political action. American Political Science Review 93:363-80.

Sowa, Jessica E., and Sally Coleman Selden. 2003. Administrative discretion and active representation: An expansion of the theory of representative bureaucracy. Public Administration Review 63:700-10.

Steffensmeier, Darrell, Jeffery Ulmer, and John Kramer. 1998. The interaction of race, gender, and age in criminal sentencing: The punishment cost of being young, black, and male. Criminology 36:763-98.

Theobald, Nick A., and Donald P. Haider-Markel. 2009. Race, bureaucracy, and symbolic representation: Interactions between citizens and police. Journal of Public Administration Research and Theory 19:409-26.

Thielemann, Gregory S., and Joseph Stewart Jr. 1996. A demand-side perspective on the importance of representative bureaucracy: AIDS, ethnicity, gender, and sexual orientation. Public Administration Review 56:168-73.

Van Gool, Bas. 2008. Untouchable bureaucracy: Unrepresentative bureaucracy in a North Indian State. Unpublished PhD Dissertation. Leiden, the Netherlands: Leiden Univ.

Vinopal, Katie. 2017. Understanding individual and organizational level representation: The case of parental involvement in schools. Journal of Public Administration Research and Theory. doi:10.1093/jopart/mux036

Watkins-Hayes, Celeste. 2011. Race, respect, and red tape: Inside the black box of racially representative bureaucracies. Journal of Public Administration Research and Theory 21 (suppl 2):i233-51.

Weber, Max. 1946. From Max Weber: Essays in sociology. H. H. Gerth and C. Wright Mills, trans. New York, NY: Oxford Univ. Press.

Wilkins, Vicky M., and Lael R. Keiser. 2004. Linking passive and active representation by gender: The case of child support agencies. Journal of Public Administration Research and Theory 16:87-102.

Wilkins, Vicky M., and Brian N. Williams. 2009. Representing blue: Representative bureaucracy and racial profiling in the Latino community. Administration \& Society 40:775-98. 